Sri Lanka J. Aquat. Sci. 21 (2) (2016): 95-103

\title{
Effects of dried, powdered carrot (Daucus carota) incorporated diet on the skin and flesh colouration of Catla catla
}

\author{
W. SANJAYA WEERAKKODY ${ }^{1 *}$ and P. RUCHIRA T. \\ CUMARANATUNGA ${ }^{2}$
}

${ }^{1}$ Department of Aquaculture and Aquatic Resources Management, University college of Anuradhapura, University of Vocational Technology, No 328, Vidyala Mawatha, Anuradhapura, Sri Lanka.

${ }^{2}$ Department of Fisheries \& Aquaculture, Faculty of Fisheries and Marine Sciences \& Technology, University of Ruhuna, Matara, Sri Lanka.

*Corresponding author (sanjaya.weerakkody146@gmail.com)

\begin{abstract}
Dull yellow coloured flesh of $C$. catla is less attractive to the consumer. Present study investigated the effects of dried, powdered carrot incorporated feed as a source of carotenoids on pigmentation and sensory properties of $C$. catla skin and flesh. Two groups of $C$. catla fingerlings $(4.39 \pm 0.13 \mathrm{~cm}$ and $2.41 \pm 0.13 \mathrm{~g})$ were fed with a commercially available feed (CF) incorporated with $100 \mathrm{mg} / \mathrm{kg}$ dried and ground $D$. carota, sieved using $250 \mu \mathrm{m}(\mathrm{CF}+\mathrm{C} 1)$ and $450 \mu \mathrm{m}(\mathrm{CF}+\mathrm{C} 2)$ mesh and it was compared with a control group of fish of the same size fed with CF. Each group included three replicates of 10 fish. Fish were fed ad libitum thrice daily for 10 weeks. Total carotenoid content in flesh and skin, average daily gain (\% ADG), specific growth rate (\% SGR), feed conversion ratio (FCR), hepato-somatic index (HSI), daily feed consumption (g/day/tank) and survival rate of fish were analysed at the end of the experiment. A sensory evaluation of fish flesh was done by a panel of judges. It was revealed that $D$. carota incorporated feed $\mathrm{CF}+\mathrm{C} 1, \mathrm{CF}+\mathrm{C} 2$ provided a significantly higher carotenoid accumulation by wet weight in flesh $(1.36 \pm 0.11$ and $1.19 \pm 0.09 \mu \mathrm{g} / \mathrm{g}$, respectively) and in skin $(2.79 \pm 0.08$ and $2.82 \pm 0.06 \mu \mathrm{g} / \mathrm{g}$, respectively), compared to flesh $(0.45 \pm 0.04 \mu \mathrm{g} / \mathrm{g})$ and skin $(0.72 \pm 0.14 \mu \mathrm{g} / \mathrm{g})$ of the $\mathrm{CF}$ fed fish. There were no significant differences ( $p>0.05$ ) among the two experimented groups in the average weight, \% SGR, daily feed consumption and \% $\mathrm{ADG}$ at the end of experiment. Significantly lower FCR was observed in $\mathrm{CF}+\mathrm{C} 1$ and $\mathrm{CF}+\mathrm{C} 2$ fed fish $(3.90 \pm 0.27,3.98 \pm 0.68$, respectively) when compared to fish fed with CF (4.91 \pm 0.39$)$. Sensory analysis revealed that the flesh of fish fed with $D$. carota predicate a bright pink colour and was preferred, compared to the flesh of control group.
\end{abstract}

Keywords: Catla catla; Daucus carota; carotenoid; sensory evaluation 


\section{Introduction}

Value is added to the aquaculture and fisheries products ranging from live finfish and shellfish to canned seafood according to different market requirements (Tietze 1998). Value addition does not necessarily mean further processing of raw materials. It can also be achieved through improvement of facilities for fishing/harvesting, postharvest handling, packaging, transportation and storage (Tietze 1998). Also, the enhancement of the colour of flesh is one of the techniques, which would help adding value to fish flesh. The pigmentation level of flesh is an important factor indicating its healthiness and quality, which affect its market value and consumer attraction.

Use of hormones and injecting synthetic colorants are widely used in the ornamental industry but its applicability in the food fish industry is questionable. Pigment enriched feed is mainly used to enhance the colour of flesh in food fish culture industry. For example, rainbow trout is fed with astaxanthin enriched feed to improve the pink colour of the flesh (Nickell and Bromage 1998).

C. catla is an exotic food fish introduced to develop culture-based fisheries of Sri Lanka and it is an important source of protein for rural communities. In fish flesh, $\beta$-carotene, astaxanthin, lutein, tunaxanthin, canthaxanthin are the responsible pigment groups, which provide yellow and reddish pink colour (Hoar and Randall 1969). Generally, flesh of $C$. catla has pale yellowish colour. Change of flesh colour to a more attractive level may improve the consumer preference for $C$. catla filet which could be made available in supermarkets as a ready-to-cook product. In this study, an attempt was made to investigate the possibility of using dented carrot with a lower economic value to produce fish fillets from $C$. catla with a higher consumer preference.

\section{Materials and Methods}

C. catla fingerlings, each with a body weight of $2.41 \pm 0.13 \mathrm{~g}$ and a standard length of $4.39 \pm 0.13 \mathrm{~cm}$ were selected for the experiment. Dented dried carrot was ground using a grinder (Jaipan, India) and sieved separately through $250 \mu \mathrm{m}$ and $450 \mu \mathrm{m}$ mesh size. A commercially available feed was used as the basal diet. Basal diet was ground and sieved using $250 \mu \mathrm{m}$ and $450 \mu \mathrm{m}$ mesh and they were separately mixed with dried carrot powder sieved with similar mesh sizes at a rate of $100 \mathrm{~g}$ of carrot powder per $\mathrm{kg}$ of basal diet and two test diets were prepared using the above mixtures separately. Hot water at about $50^{\circ} \mathrm{C}$ was added to each of the mixtures and the basal diet separately until a non-sticky dough was formed. Then pellets were prepared using the pellet machine with $1 \mathrm{~mm}$ sieve plate. The pellets were air dried for 24 hours and dried at $50^{\circ} \mathrm{C}$ in an oven (UM400, Memmert, Germany) for 3 hours. Dried pellets were packed in polythene bags and stored in the refrigerator until they were used. Pellets prepared only with commercially available feed was used as basal diet (CF) while diets with commercially available feed with $250 \mu \mathrm{m}$ and $450 \mu \mathrm{m}$ sieved carrot powder were used as test diets, $\mathrm{CF}+\mathrm{C} 1$ and $\mathrm{CF}+\mathrm{C} 2$, respectively.

C. catla fingerlings brought to the laboratory were initially fed with the commercially available feed (basal diet) ad libitum for one month prior to 
commencement of the experiment in order to acclimatize them into the experimental conditions. After acclimation, their weight and length were measured to obtain the initial values and 3 fish were sacrificed to analyse the initial carotenoid levels in flesh and skin and they were divided into three groups each consisting of 3 tanks. Ten $C$. catla fingerlings per tank were randomly introduced into 9 rearing fibreglass tanks. Fish were selected irrespective of their sex, due to the inability to identify the sex using morphological characters. One group was fed with the basal diet (CF) and other two with two test diets, $\mathrm{CF}+\mathrm{C} 1$ and $\mathrm{CF}+\mathrm{C} 2$ containing powdered carrot. They were fed ad libitum three times daily ( $8 \mathrm{am}, 12$ noon and $4 \mathrm{pm}$ ). Daily feed consumption by fish in each experimental group was measured separately. This was done by using known weights of feed before feeding, weighing the feed left after feeding and obtaining the difference in weight of feed before and after feeding as feed consumed by each group of fish.

\section{Proximate Analysis}

The prepared carrot powder and all three diets $(\mathrm{CD}, \mathrm{CD}+\mathrm{C} 1$ and $\mathrm{CD}+\mathrm{C} 2)$ were grounded into a finer powder using a porcelain mortar and a pestle. The chemical composition of each sample was then determined by proximate analysis based on the method described in Official Methods of Analysis of the Official Association of Analytical Chemists (1990)

\section{Growth parameters of fish}

Using the total body weight and daily feed consumption data, \% average daily gain (\% ADG), Specific growth rate (SGR) and Feed Conversion Ratio (FCR) were determined.

\section{Total carotenoid content in flesh and skin}

Total carotenoid content in flesh and skin was determined by method described by Yanar et al. (2005). Three fish from each replicate were sacrificed without using chemicals. Flesh, skin and fins were separated and grounded separately. One gram of each of the samples was transferred into a dry glass tube. Ten $\mathrm{ml}$ of dry acetone was added and mixed using a glass rod. Anhydrous $\mathrm{Na}_{2} \mathrm{SO}_{4}(2 \mathrm{~g})$ was added and mixture was centrifuged at $5000 \mathrm{rpm}$ for 5 minutes. The sealed glass tubes were then stored at $4^{\circ} \mathrm{C}$. After 3 days, supernatant of the extract was carefully drained off, and absorbance was measured at $476 \mathrm{~nm}$ using a UV spectrophotometer (HACS, DR4000U).

$$
\text { Total carotenoid content }=\frac{\text { (absorption of maximum wave length) } \mathrm{X} 10}{0.25 \mathrm{X} \text { sample weight }(\mathrm{g})}
$$

where, dilution factor $=10$, and extraction coefficient $=0.25$ 


\section{Sensory evaluation}

Sensory evaluation was performed by displaying samples of fish fillet obtained from fish fed with the three experimental feeds without providing any identification labels and 11 students from the Faculty of Fisheries and Marine Sciences \& Technology, University of Ruhuna were requested to record their preference along a four point hedonic scale varied from 1 (appearance is not attractive), 2 (appearance is not different), 3 (Appearance is good) and 4 (appearance is very attractive).

\section{Statistical analysis}

All the data were tested for normality of distribution and homogeneity of variance. Data on growth parameters and pigment levels of fish, which were recorded separately for each treatment diet, were analysed by one-way ANOVA from SPSS 16.0 Software package. A minimum significance level of $\mathrm{p}<0.05$ was used in all tests.

\section{Results}

There was no difference in skin colour within first two weeks in fish fed with control and test diets. After 2 weeks in fish fed with powdered carrot incorporated diets indicated a slight pink body coloration. At the end of 10 weeks of experimental period, total carotenoid content in the skin and flesh of fish that fed with experimental diets, $\mathrm{CF}+\mathrm{C} 1$ and $\mathrm{CF}+\mathrm{C} 2$ and $\mathrm{CF}$ indicated higher values $(2.79 \pm 0.08,2.82 \pm 0.06$ and $0.72 \pm 0.14 \mu \mathrm{g} / \mathrm{g}$ in skin; and $1.36 \pm 0.11,1.19 \pm 0.09$ and $0.45 \pm 0.04 \mu \mathrm{g} / \mathrm{g}$ in flesh, respectively), compared to the initial pigment levels $(0.72 \pm 0.14$ in skin and $0.45 \pm 0.04$ in flesh). Carotenoid content in flesh and skin of fish fed with $\mathrm{CF}+\mathrm{C} 1 \& \mathrm{CF}+\mathrm{C} 2$ was not significantly different ( $p>0.05)$, Carotenoid contents in fish fed two test diets were significantly higher than the carotenoid content of CF fed fish $(\mathrm{p}<0.05$; Table 1$)$.

Table 1. Initial and final mean $\pm \mathrm{SD}(\mathrm{n}=3)$ total carotenoid content $(\mu \mathrm{g} / \mathrm{g})$ of the skin and flesh of the $C$. catla fed on experimental diets.

\begin{tabular}{lllll}
\hline \multirow{2}{*}{ Sample } & & \multicolumn{3}{l}{ Carotenoid content in experimental diets $(\mu \mathrm{g} / \mathrm{g})$} \\
\cline { 3 - 5 } & & $\mathrm{CF}$ & $\mathrm{CF}+\mathrm{C} 1$ & $\mathrm{CF}+\mathrm{C} 2$ \\
\hline \multirow{2}{*}{ Initial } & Skin & $0.58 \pm 0.02^{\mathrm{a}}$ & $0.58 \pm 0.02^{\mathrm{a}}$ & $0.58 \pm 0.02^{\mathrm{a}}$ \\
& Flesh & $0.11 \pm 0.04^{\mathrm{a}}$ & $0.11 \pm 0.04^{\mathrm{a}}$ & $0.11 \pm 0.04^{\mathrm{a}}$ \\
\multirow{2}{*}{ Final } & Skin & $0.72 \pm 0.14^{\mathrm{a}}$ & $2.79 \pm 0.08^{\mathrm{b}}$ & $2.82 \pm 0.06^{\mathrm{b}}$ \\
& Flesh & $0.45 \pm 0.04^{\mathrm{a}}$ & $1.36 \pm 0.11^{\mathrm{b}}$ & $1.19 \pm 0.09^{\mathrm{b}}$ \\
\hline
\end{tabular}

Means with different superscripts in each row $(a, b)$ were significantly different from each other $(\mathrm{p}<0.05)$.

A light red tint colour was observed in the fillets of the fish that were fed with the $\mathrm{CF}+\mathrm{C} 1$ and $\mathrm{CF}+\mathrm{C} 2$ when compared to the fish fed with the $\mathrm{CF}$ (Plate 1). Red 
colour was prominent in the muscles closed to the back bone. A prominent yellowish colour was observed in the fillets of fish which were fed on $\mathrm{CF}$.

(A)

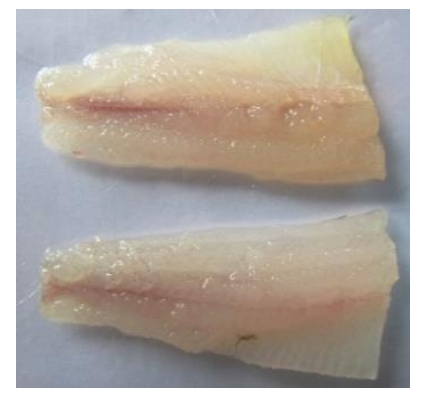

(B)

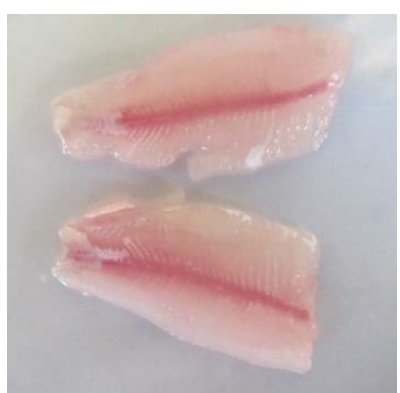

(C)

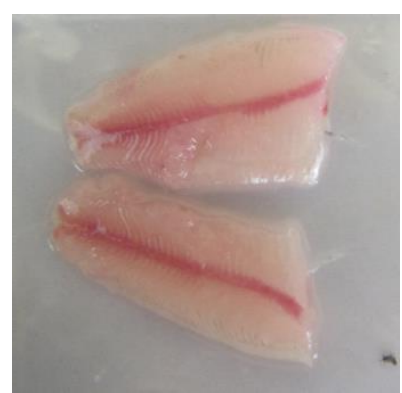

Plate 1. Fillets of the $C$. catla fed with experimental diets CF (A) showing pale yellow colour and $\mathrm{CF}+\mathrm{C} 1(\mathrm{~B})$ and $\mathrm{CF}+\mathrm{C} 2(\mathrm{C})$ showing the reddish tint colour.

Mean ranks of acceptance recorded for fillet of $C$. catla fed with $\mathrm{CF}+\mathrm{C} 1$ and $\mathrm{CF}+\mathrm{C} 2$ when evaluated along a four point via hedonic scale for sensory evaluation (3.55 \pm 0.13 and $1.32 \pm 0.19$ respectively) were significantly higher $(\mathrm{p}<0.05)$ compared to the rank of acceptance received by the fillet of fish fed with $\mathrm{CF}$ (3.41 \pm 0.45 ; Figure 1).

Growth, \%SGR and \%ADG of fish did not show any difference between experimental groups (Table 2). Nevertheless, FCR was significantly lower in the fish fed with carotenoid $(3.90 \pm 0.27,3.98 \pm 0.68$ for $\mathrm{CF}+\mathrm{C} 1$ and $\mathrm{CF}+\mathrm{C} 2$ respectively) than fish fed with control diet $(4.91 \pm 0.39)$.

Table 2. Mean \pm SD $(n=3)$ of growth performance and feed utilization efficiencies of C. catla fed with experimental diets.

\begin{tabular}{lccc}
\hline Parameter & \multicolumn{3}{c}{ Experimental diets $(\mathrm{n}=3)$} \\
\cline { 2 - 4 } & $\mathrm{CF}$ & $\mathrm{CF}+\mathrm{C} 1$ & $\mathrm{CF}+\mathrm{C} 2$ \\
\hline \% SGR & $1.35 \pm 0.45^{\mathrm{a}}$ & $1.47 \pm 0.09^{\mathrm{a}}$ & $1.40 \pm 0.11^{\mathrm{a}}$ \\
\% ADG & $2.34 \pm 0.45^{\mathrm{a}}$ & $2.65 \pm 0.35^{\mathrm{a}}$ & $2.88 \pm 0.31^{\mathrm{a}}$ \\
FCR & $4.91 \pm 0.39^{\mathrm{a}}$ & $3.90 \pm 0.27^{\mathrm{b}}$ & $3.98 \pm 0.68^{\mathrm{b}}$ \\
$\%$ survival & $90 \pm 5$ & $100 \pm 0$ & $96.7 \pm 3.4$ \\
$\begin{array}{l}\text { Daily food consumption rate } \\
\text { (g/day/tank) }\end{array}$ & $0.95 \pm 0.08^{\mathrm{a}}$ & $0.90 \pm 0.06^{\mathrm{a}}$ & $0.83 \pm 0.06^{\mathrm{a}}$ \\
\hline
\end{tabular}

Means with different superscripts in each row $(a, b)$ are significantly different from each other $(\mathrm{p}<0.05)$. 


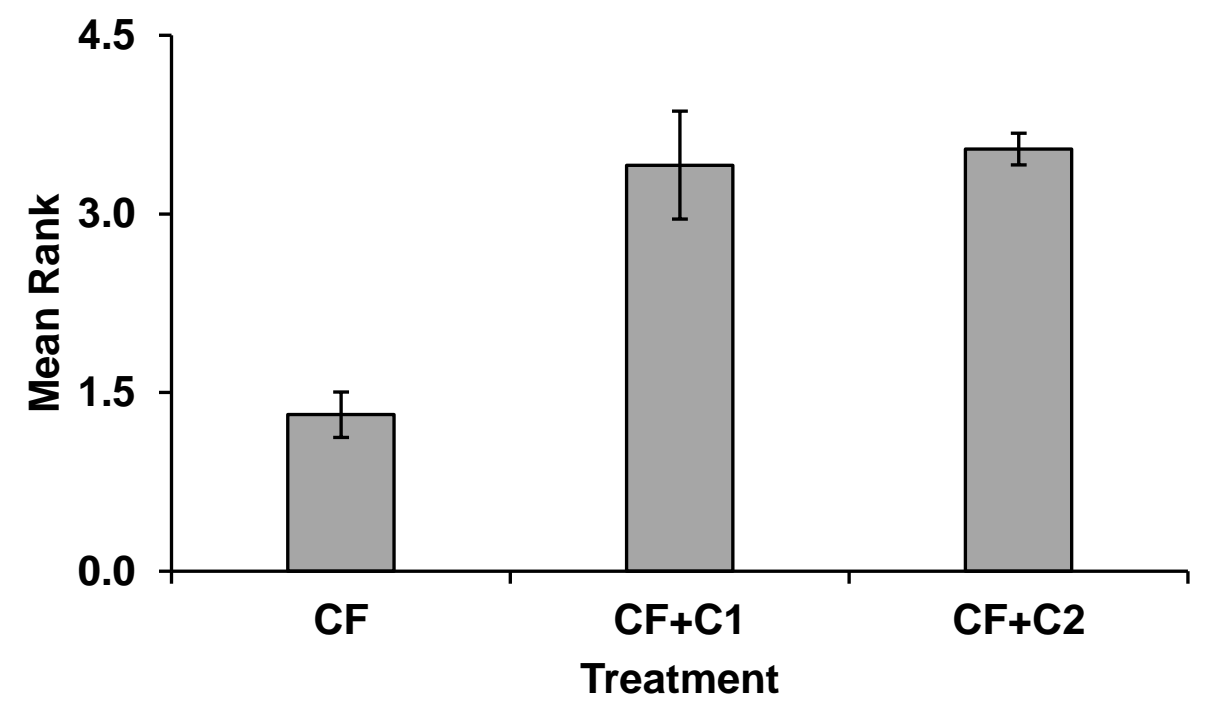

Figure 1. Mean \pm SD total rank percentage of acceptance of fillet of $C$. catla in three experimental groups as evaluated along a four point via hedonic scale.

\section{Discussion}

Bright pink colour fillets produced by $C$. catla fed with diets formulated with powdered carrot looked more attractive than yellow colour fillet produced by fish fed with CF. Yellow colour of the latter may have been developed due to the presence of plant materials such as cereals and cereal by-products (Gupta et al. 2006), which contain plant pigments such as lutein included in commercial feed, which was used as the control diet (CF). $\beta$-carotene is the principle pigment in carrot, which gives a red orange appearance (Pintheiro et al. 1998). When the fish ingest the $\beta$-carotene, these are slowly transformed to the astaxanthin in the gut (Tietze 1998). When the fish get sufficient amount of $\beta$-carotene, excess will be deposited as astaxanthin to give the bright pink colour to the flesh and the skin (Gupta et al. 2006). C. catla may have the ability to convert these supplement $\beta$-carotene to astaxanthin and change the flesh colour to a bright pink. Conversion of $\beta$-carotene to the esterified form of astaxanthin may be dominant over the lutein in fish, to produce a pink colour in the flesh and skin of fish fed with feed supplemented with powdered carrot. After death of fish, colour of flesh is not affected by their body function (Sigholt et al. 1997).

Consequently, the study indicated that the use of vegetable carotenoid source (D. carota) have many positive effects on the pigmentation of $C$. catla. The dietary carotenoid content and total carotenoid content in flesh and skin of $C$. catla were higher than the initial total carotenoid content in flesh and skin which is a clear indication of active uptake of carotenoid pigments in carrot by the skin and the flesh of $C$. catla. Longitudinal variation in carotenoid content in the body and bright pinkish colour was found in every treated fish fed with experimental diets $(\mathrm{CF}+\mathrm{C} 1$ and $\mathrm{CF}+\mathrm{C} 2$ ) when compared to the fish fed with the control diet $(\mathrm{CF})$. More reddish 
colour was observed closer to the caudal area than the anterior part due to excess deposition of carotenoid pigment in that area. Christianes and Wallae (1988) and No and Storebakken (1991) have shown that caudal part of fish may contain 30-40\% more carotenoids than the back and neck part of the fillet. Bjerkeng et al. (1992) reported that longitudinal variation in carotenoid content and red colour of the fish flesh, which indicates that higher carotenoid deposition occurs in the caudal area than in anterior part of the body of salmonid fishes. This can occur due to the rapid deposition of carotenoids close to the backbone. Similar results have been reported by Mccallum et al. (1987), where colour increment in dorsal and midline cut area has been higher than in other areas.

Higher total carotenoid content was observed during the present study, in the skin of $C$. catla fed with experimental diet compared to the initial carotenoid content in skin (Table 1). In the present study, higher carotenoid content was observed in fish fed with $\beta$-carotenoid supplemented diet than fish fed with basal diet. Similar results were reported by Kaliniwski et al. (2005) in the skin of Pagrus pagrus and pigmentation of skin was modified from a dark grey to reddish pink by providing a supplementary diet with carotenoids. Environmental factors such as temperature, $\mathrm{pH}$ and dissolved oxygen will also determine the skin pigmentation while handling stress and method of sacrifice also have been known to provide negative influence on coloration of fish skin (Lin et al. 1998)

Carotenes are known to have a positive role in intermediate metabolism of fish (Tacon cited in Kalinowski et al. 2005). It helps to enhance the nutrient utilization, which may result in growth improvement of fish (Amar et al. 2001). In the present study, growth, \% SGR and \% ADG of fish did not show any differences among experimental groups (Table 2). Similar results were reported by Nickell and Bromage (1998) with respect to rainbow trout. Significantly lower FCR in fish fed with carrot included diets indicates a reduction in the feed cost, which generally accounts for a considerable portion of total production cost in aquaculture.

Sensory analysis of the present study also indicates that sensory properties of fillet colour help to increase the consumer attraction. $\beta$-carotenoid from carrot gives the orange colour (Pintheiro et al. 1998). Nevertheless, after the absorbance by the fish, it turns to a bright pink colour due to the metabolism of beta carotenoids (Gupta et al. 2006). Bright pink colour fillets is more attractive and have a higher consumer preference. Considering the results of the present study, it could be recommended that, in order to improve the consumer preference and the market value for Catla, their flesh and skin colouration could be improved by feeding with diets containing powdered carrot. However, preparation cost of the pigment included fish feed should be minimized in order to achieve higher economic gains. By using dented carrot for this purpose, which has no market value, preparation of carotenoid feed could be kept at economically feasible levels and furthermore economic gains to carrot growers in Sri Lanka could be improved. In order to increase the economic gains through $C$. catla, which is an exotic species used in culture-based fisheries of Sri Lanka, investigations should be carried out to produce value added products with higher consumer preference; improvement of skin and flesh colouration could be considered as one of such possibilities. It is a fact that consumer demand for exotic cichlid species (Oreochromis mossambicus and O. niloticus) is much higher in rural areas of Sri 
Lanka compared to exotic carp species including C. catla (Amarasinghe et al. 1989; Amarasinghe 2002, 2010). With the future prospects of development of culture-based fisheries in Sri Lanka (Amarasinghe 2013), value addition of exotic carps is imperative to increase consumer preference. The present study envisages that there is a possibility to enhance coloration of skin and flesh coloration of $C$. catla using dried powdered dented $D$. carota as a feed supplement. Further investigations are necessary to identify the optimum particle size of dried carrot and percentage of D. carota to be included in fish feed.

\section{Acknowledgement}

We gratefully acknowledge the facilities provided by the Department of Fisheries and Aquaculture, Faculty of Fisheries and Marine Sciences \& Technology, University of Ruhuna for providing us the necessary facilities for the successful completion of this project.

\section{References}

Amar E., V. Kiron, S. Satoh \& T. Watanabe 2001. Influence of various dietary synthetic carotenoids on bio-defence mechanisms in rainbow trout, Oncorhynchus mykiss (Walbaum). Aquaculture 33(1): 162-173. doi: 10.1046/j.1355-557x.2001.00051.x

Amarasinghe U.S. 2002. The Fishery and population dynamics of Oreochromis mossambicus and Oreochromis niloticus (Osteichthyes, Cichlidae) in a shallow irrigation reservoir in Sri Lanka. Asian Fisheries Science 15(1): 720.

Amarasinghe U.S. 2010. Inland fisheries resource enhancement and conservation in Sri Lanka. pp. 113-132. In: Miao Weimin, Sena De Silva and Brian Davy (eds), Inland Fisheries Resource Enhancement and Conservation in Asia. FAO RAP Publication 2010/22, FAO Regional Office for Asia and the Pacific, Bangkok.

Amarasinghe U.S. 2013. Fisheries resources in alleviation of hunger and malnutrition in Sri Lanka - accomplishment and challenges. Sri Lanka Journal of Aquatic Sciences 18: 1-15. doi: http://dx.doi.org/10.4038/sljas.v18i0.7034

Amarasinghe U.S., S.S. De Silva \& J. Moreau 1989. Spatial changes in growth and mortality and effects on the fishery of Oreochromis mossambicus (Pisces, Cichlidae) in a man-made lake in Sri Lanka. Asian Fisheries Science 3: 57-68.

AOAC 1990. Official Methods of Analysis of the Official Association of Analytical Chemists. 15th edition. Arlington, Virginia.

Bjerkeing B., T. Storebakken \& L.S. Jensen 1992. Pigmentation of rainbow trout from start feeding to sexual maturation. Aquaculture 108(3-4): 333-346. doi: 10.1016/0044-8486(92)90117-4

Christiansen J.S. \& J.C. Wallae 1988. Deposition of canthaxanthin and muscle lipid in two size groups of Arctic Charr, Salvelinus alpinus. Aquaculture 69(1-2): 69-78. doi: $10.1016 / 0044-8486(88) 90187-1$ 
Gupta S. K., A.K. Jha, A.K. Pal \& G. Venkateshwarlu 2006. Use of natural carotenoids for pigmentation in fishes. Natural Product Radiance 6(1): 46-49.

Hoar W.S. \& D. J. Randall 1969. Fish physiology. III edition. Academic Press, London.

Kalinowski C.T., L.E. Robaina, H. Fernaindez-Palacios, D. Schuchardt \& M. Izquierdo 2005. Effect of different carotenoid sources and their dietary levels on red porgy (Pagrus pagrus) growth and skin colour. Aquaculture 244(1-4): 223231. doi: 10.1016/j.aquaculture.2004.11.001

Lin M., H. Ushio, T. Ohshima, H. Yamanaka \& C. Koizumi 1998. Skin color control of the Red sea bream (Pagrus major). LWT-Food Science and Technology 31(1): 27-32. doi: 10.1006/fstl.1997.0280

Mccallum I.M., K.M. Cheng, \& B.E. March 1987. Carotenoid pigmentation in two strains of Arctic Chinook salmon (Oncorhynchus tshawytscha) and their crosses. Aquaculture 67(3-4): 291-300. doi: 10.1016/0044-8486(87)90214-6

Nickell D. \& N. Bromage 1998. The effect of timing and duration of feeding astaxanthin on the development and variation of fillet color and efficiency of pigmentation in rainbow trout (Oncorhynchus mykiss). Aquaculture 169(3-4): 233-246. doi: 10.1016/S0044-8486(98)00385-8

No H.K. \& J. Storebaklen 1991. Color stability of rainbow trout fillets during frozen storage. Food Sciences 56(4): 972-984. doi: 10.1111/j.13652621.1991.tb14618.x

Pintheiro-Santaana H.M., P.C. Stringheta, S.C.C. Brandão, H.H. Páez \& V.M.V de Queiróz 1998. Evaluation of total carotenoids, alpha- and beta-carotene in carrot (Daucus carota $\mathrm{L}$ ) during home processing. Ciencia e Tecnologia de Aliment 18(1): 39-44. http://dx.doi.org/10.1590/S0101-20611998000100009

Sigholt T., U. Erikson, T. Rustad, S. Johansen, T.S. Nordtvedt \& A. Seland 1997. Handling stress and storage temperature affect meat quality of farmed-raised Atlantic salmon (Salmo salar). Food Science 62(4): 898-905. doi: 10.1111/j.1365-2621.1997.tb15482.x

Tietze U. 1998. Report of the Workshop on Financing Value-added Production and Marketing of Fishery Products in Asia and the Pacific. Kuala Lumpur, Malaysia, 26-30 May 1997. FAO Fisheries Report No. 577. FAO, Rome. 117 p.

Yanar Y., H. Büyükçapar, M. Yanar \& M. Göcer 2007. Effect of carotenoids from red pepper and marigold flower on pigmentation, sensory properties and fatty acid composition of rainbow trout. Food Chemistry 100(1): 326-330. doi:10.1016/j.foodchem.2005.09.056 